\title{
Pricing and Lot Sizing for Seasonal Products in Price Sensitive Environment
}

\author{
S. Panda ${ }^{1}$ and S. Saha ${ }^{2}$ \\ ${ }^{1}$ Department of Mathematics, Bengal Institute of Technology, No. 1 Govt. Colony Kolkata 700150, \\ West Bengal, India \\ ${ }^{2}$ Department of Mathematics, Institute of Engineering \& Management, Salt Lake Electronic Complex, Kolkata-700091, \\ West Bengal, India
}

Correspondence should be addressed to S. Panda; shibaji.panda@gmail.com

Received 13 February 2013; Accepted 7 March 2013

Academic Editors: G. Dósa, A. Rossi, and R. Varela

Copyright (c) 2013 S. Panda and S. Saha. This is an open access article distributed under the Creative Commons Attribution License, which permits unrestricted use, distribution, and reproduction in any medium, provided the original work is properly cited.

Some seasonal products have limited sales season, and the demand of such products over the sales season is of increasing-steadydecreasing type. Customers are highly sensitive to the prices of the products. In such situation, adjustment of unit selling price is needed to accelerate inventory depletion rate and for determining order quantity for the sales season. In this paper, we focus on the issue by jointly determining optimal unit selling prices and optimal lot size over the sales season. Unlike the conventional inventory models with pricing strategy, which were restricted to prespecified pricing cycle lengths, that is, fixed number of price changes over the time horizon, we allow the number of price changes to be a decision variable. The mathematical model is developed and existence of optimal solution is verified. A solution procedure is developed to determine optimal prices, optimal number of pricing cycles, and optimal lot size. The model is illustrated by a numerical example. Sensitivity analysis of the model is also carried out.

\section{Introduction}

Items like fashion apparel, hi-tech product parts, periodicals, Christmas accessories, and so forth, have limited sales season and become outdated at end of season. Demand of such products is sensitive to time as well as price. Initially after introduction of the product, demand increases up to a point of time then it becomes steady. Finally towards end the of the season, it decreases. Ramp-type time-dependent demand pattern is very close to the demand pattern in such situations. The inventory model with ramp-type demand rate was first proposed by Hill [1]. Since then many researchers and practitioners have given considerable attention to analyze ramp-type demand. Mandal and Pal [2] have extended the inventory model with ramp-type demand for exponentially deteriorating items by allowing shortages. Wu and Ouyang [3] have developed an inventory model by considering two different replenishment policies: shortage followed by inventory and inventory followed by shortage. Wu [4] has further proposed an inventory model for deteriorating items with ramp-type demand, Weibull distribution deteriorating rate, and waiting time-dependent partial backlogging rate. Giri et al. [5] have extended ramp-type demand inventory model with more general Weibull distribution deterioration rate. Manna and Chaudhuri [6] have developed a production inventory model with ramp-type two time periods classified demand pattern where the finite production rate depends on demand. Deng et al. [7] have pointed out the questionable results obtained by Mandal and Pal [2] and Wu and Ouyang [3] and have provided a more reliable solution. Panda et al. $[8,9]$ have extended Giri et al.'s [5] two time periods classified demand model to three time periods. Cheng and Wang [10] have extended the model proposed by Hill [1] by assuming trapezoidal-type demand rate, which is a piece wise linear function of time. But they have only considered the situation of completely backlogging. They have used the logic that for fashionable products as well as for seasonal products, steady demand after its exponential increment must not be continued indefinitely. Recently, Panda et al. [11] have developed a single-item economic production quantity (EPQ) model with quadratic ramp-type demand function. In their model, they have determined optimal production 
stopping time to maximize total unit profit of the system. Skouri et al. [12] have extended Deng et al. [7] by introducing more general ramp-type demand rate, Weibull distribution deterioration rate, and general partial backlogging rate that is a function of waiting time up to the next replenishment. Hung [13] has extend Skouri et al. [12] by considering arbitrary component in ramp-type demand pattern. Saha and Basu [14] have developed inventory model with two component ramptype demand, which is function of time as well as price. It may be easily observed that in all the above-mentioned papers, those analyze ramp-type demand under variety of modelling assumptions, effects of price sensitivity have been ignored though demand of seasonal product is price sensitive. At the same time effect of dynamic pricing in ramp-type demand environment has not been analyzed.

On the other hand, pricing is one of the major problems for organizations dealing with inventory. The organization has to decide how much to ask for each unit and when to drop the price as season rolls on. Firm that sells inventory of a seasonal product has long been using various innovative sales promotion tools in stimulating short-term sales. As a result, sales promotions scheme becomes a vital tool for marketers and its importance has been increasing significantly over the years. Sales promotions are classified as price and nonprice based on the nature of promotions [15]. This has led many researchers to investigate inventory models with pricesensitive demand. Urban and Baker [16] have developed an inventory model where they have assumed demand as a multivariable function of price. Shinn and Hwang [17] have formulated an inventory model with convex price-dependent demand and lot-size-dependent delay in payments. In this direction, the works of Dave et al. [18], N. H. Shah and Y. K. Shah [19], Wee and Law [20], Khouja [21], and Wu et al. [22] are worth mentioning. Transchel and Minner [23] have proposed a dynamic pricing policy in a single market with outcompetition where demand is solely dependent on price. They have determined joint optimal lotsize and prices over a finite time horizon. Netessine [24] has developed a dynamic pricing policy where demand is time and price-dependent but the policy suits for revenue management. Adida and Perakis [25] have developed inventory model with dynamic pricing by using optimal control theory. In this direction, interested readers may consult the survey paper of Elmaghraby and Keskinocak [26].

As indicated, dynamic analysis of optimal joint pricing and inventory control problem has recently become popular for researcher as well as practitioners. But inventory models focusing on dynamic pricing and lot sizing decision have assumed demand as price or time or both time and pricedependent and none has tried to represent demand as ramptype time-dependent function which is also sensitive to price. Motivated by true implementation of dynamic pricing, we focus on determining the optimal policy for a modeling paradigm with ramp-type time and price-dependent demand. This paper makes three major contributions. Our first contribution is analyzing the dynamic pricing problem with a limited number of price changes and providing insights into pricing and timing decisions. Most of the related papers either permit for continuous price changes or presume that the firm operates in a multiple-period environment with time-invariant demand characteristics in each period. The former assumption differs from our work since we assume that the total number of times and that price can be changed are limited, which is significant when there are costs associated with each change. The latter assumption also differs from our work since we model demand during the period as a more general time-dependent ramp-type function of time. This type of demand pattern with price sensitivity is most relevant for the products that belong to seasonal class because of the limited sales season and nature of their requirements. Our second contribution is that instead of focusing on a specific price trajectory, we employ a more general model with a minimal number of assumptions that can incorporate both price increases and decreases and establish when one or the other situation arises, thus making the results applicable to a variety of industries. Finally, we develop a suitable algorithm to determine the number of price changes, joint optimal lot size and optimal prices for maximizing profit over the finite season.

\section{Mathematical Modelling and Analysis}

Consider a retailer sales seasonal products over a finite season $L$. Demand of the product is price and time-dependent continuous ramp-type function is of the form:

$$
D\left(t, p_{l i}\right)=A e^{[b\{t-(t-\mu) H(t-\mu)-(t-\gamma) H(t-\gamma)\}]}-\beta p_{l i},
$$

where $A>0$ is the initial rate of demand, $b>0$ is the time-sensitive parameter of demand, and $\beta>0$ is the price sensitive parameter of demand. $p_{l i}$ is the unit selling price of the product in the $i$ th pricing cycle of the $l$ th time period $(l=1,2,3) \cdot H(t-\mu)$ and $H(t-\gamma)$ are well-known Heaviside's functions, respectively, defined as

$$
H(t-X)= \begin{cases}1, & \text { if } t \geq X \\ 0, & \text { if } t<X\end{cases}
$$

where $X=\mu$ or $\gamma$. Here, demand increases exponentially up to time $\mu$. In the interval $[\mu, \gamma]$, it is steady only that its fluctuation occurs for the change of price in different pricing cycles. After time $\gamma$, it decreases exponentially and becomes asymptotic. Note that we assume that the demand of the product over the sales season is of increasing-steadydecreasing type. However, the market potential of the product is affected for time and price dependency of demand. Unit selling price of the product has considerable impact on customers purchases but it is too far less than the impact of seasonal utility and necessity of the product in the finite time frame. Thus, it is quite appropriate to assume increasingsteady-decreasing demand pattern over the season though market potential is affected by both time and price. We assume that $n$ price changes are applied with a fixed cost $c_{0}$ associated with each price change. The maximum number of allowable price change is $n_{\max }$. We impose a restriction on the maximum number of price changes to indicate that too many price changes have negative effect on customers, because it may impress customers by the quality and availability of the 
product. At the same time it also incurs huge amount of price change cost on total profit for publicity and advertisement. Let $c$ be the unit purchase cost of the product, $h$ the holding cost per unit time, and $s$ is the setup cost. At the beginning of the season $Q$ amount of inventory is replenished. Then, as time progresses inventory level decreases due to demand and ultimately reaches zero level at the end of the season $L$. Demand is time and price-dependent and it is three time periods classified. We assume that time horizon $L$ is the combination of three time periods $[0, \mu],[\mu, \gamma]$, and $[\gamma, L]$ and $n_{1}, n_{2}$, and $n_{3}$ numbers of pricing cycles of lengths $T_{1}, T_{2}$, and $T_{3}$ are considered in the time periods $[0, \mu],[\mu, \gamma]$, and $[\gamma, L]$, respectively, such that $n_{1}+n_{2}+n_{3}=n \leq n_{\max }$. We also assume that $Q_{1 n_{1}}, Q_{2 n}$, and $Q_{3 n_{3}}$ units of inventories are depleted in time periods $[0, \mu],[\mu, \gamma]$, and $[\gamma, L]$, respectively, such that $Q_{1 n_{1}}+Q_{2 n_{3}}+Q_{3 n_{3}}=Q$. Here, our objective is to determine values of $\left\{p_{1 i_{1}}, i_{1}=1,2, \ldots, n_{1}\right\},\left\{p_{2 i_{2}}, i_{2}=1,2, \ldots, n_{2}\right\}$, $\left\{p_{3 i_{3}}, i_{3}=1,2, \ldots, n_{3}\right\}, n_{1}, n_{2}$, and $n_{3}$ such that total profit for the season $L$ is maximum. Note that, products sold in these three time periods are replenished at the beginning of the season $L$. The initial inventory level in the time period $[\mu, \gamma]$ is assumed as the last inventory level of $[0, \mu]$, and that of $[\gamma, L]$ is the last inventory level of $[\mu, \gamma]$. The number of price changes is interrelated by the relation $n_{1}+n_{2}+n_{3} \leq n_{\max }$. We calculate the profit functions in these three time periods separately and combination of these in unique proportion will certainly provide the total profit of the system over the season $L$.

2.1. Model Formulation. In time interval $[0, \mu]$, a number of pricing cycles $n_{1}$ are considered each of length $T_{1}$ such that $n_{1} T_{1}=\mu$. Let $Q_{1 i_{1}}$ be the sales amount from starting of the sales season to $i_{1}$ th period $\left[\left(i_{1}-1\right) T_{1}, i_{1} T_{1}\right],\left(i_{1}=1,2, \ldots, n_{1}\right)$. Then, we have

$$
\begin{aligned}
Q_{1 i_{1}} & =\sum_{j=1}^{i_{1}} \int_{(j-1) T_{1}}^{j T_{1}} D\left(t, p_{1 j}\right) d t \\
& =\frac{A}{b}\left(e^{i_{1} b T_{1}}-1\right)-\beta T_{1} \sum_{j=1}^{i_{1}} p_{1 j} .
\end{aligned}
$$

Let $I_{1 i_{1}}(t),\left(i_{1}=1,2, \ldots, n_{1}\right)$ be the instantaneous level of inventory at time $t$ in the $i_{1}$ th replenishment cycle. Then, instantaneous inventory level is governed by

$$
\frac{d I_{1 i_{1}}(t)}{d t}=-D\left[t, p_{1 i_{1}}\right], \quad\left(i_{1}-1\right) T_{1} \leq t \leq i_{1} T_{1}
$$

with initial condition $I_{1 i_{1}}\left(\left(i_{1}-1\right) T_{1}\right)=Q-Q_{1 i_{1-1}}$.

Solving the differential equation, we have

$$
\begin{aligned}
& I_{1 i_{1}}(t)=Q-\frac{A}{b}\left(e^{b t}-1\right) \\
&+\beta T_{1} \sum_{j=1}^{i_{1}-1} p_{1 j}+\beta p_{1 i_{1}}\left(t-\left(i_{1}-1\right) T_{1}\right), \\
&\left(i_{1}-1\right) T_{1} \leq t \leq i_{1} T_{1} .
\end{aligned}
$$

Holding cost of inventory in time period $[0, \mu]$ is given by

$$
\begin{aligned}
\mathrm{HC}_{1}= & \sum_{j=1}^{n_{1}} h \int_{(i-1) T_{1}}^{i T_{1}} I_{1 i_{1}}(t) d t \\
= & h Q n_{1} T_{1}+\frac{n_{1} h A T_{1}}{b}-\frac{A h}{b^{2}}\left(e^{n_{1} b T_{1}}-1\right) \\
& +\frac{h \beta T_{1}^{2}}{2} \sum_{i_{1}=1}^{n_{1}} p_{1 i_{1}}+h \beta T_{1}^{2} \sum_{i_{1}=1}^{n_{1}-1}\left(n_{1}-i_{1}\right) p_{1 i_{1}} .
\end{aligned}
$$

Sales revenue for the time period $[0, \mu]$ is

$$
\begin{aligned}
\mathrm{SR}_{1} & =\sum_{i_{1}=1}^{n_{1}} p_{1 i_{1}} \int_{\left(i_{1}-1\right) T_{1}}^{i_{1} T_{1}} D\left(t, p_{1 i_{1}}\right) d t \\
& =\frac{A}{b}\left(1-e^{-b T_{1}}\right) \sum_{i_{1}=1}^{n_{1}} p_{1 i_{1}} e^{i_{1} b T_{1}}-\beta T_{1} \sum_{i_{1}=1}^{n_{1}} p_{1 i_{1}}^{2} .
\end{aligned}
$$

In interval $[\mu, \gamma]$, a number of pricing cycles $n_{2}$ are considered and each of length $T_{2}$; that is, $n_{2} T_{2}=\gamma-\mu$. The demand is independent of time in this interval. Only its fluctuation occurs for different prices in different pricing cycles. Let $Q_{2} i_{2}$ be sales amount from time $\mu$ to end of $i_{2}$ th period $\left[\mu+\left(i_{2}-\right.\right.$ 1) $\left.T_{2}, \mu+i_{2} T_{2}\right],\left(i_{2}=1,2, \ldots, n_{2}\right)$. Then, we have

$$
\begin{aligned}
Q_{2 i_{2}} & =\sum_{j=1}^{i_{2}} \int_{\mu+(j-1) T_{2}}^{\mu+j T_{2}} D\left(t, p_{2 j}\right) d t \\
& =i_{2} A T_{2} e^{b \mu}-\beta T_{2} \sum_{j=1}^{i_{2}} p_{2 j} .
\end{aligned}
$$

Let $I_{2 i_{2}}(t),\left(i_{2}=1,2, \ldots, n_{2}\right)$ be the instantaneous level of inventory at time $t$ in $i_{2}$ th replenishment cycle in $[\mu, \gamma]$. Then, the governing differential equation is

$$
\begin{aligned}
& \frac{d I_{2 i_{2}}(t)}{d t}=-D\left[t, p_{2 i_{2}}\right], \\
& \mu+\left(i_{2}-1\right) T_{2} \leq t \leq \mu+i_{2} T_{2}
\end{aligned}
$$

with initial condition $I_{2 i_{2}}\left(\mu+\left(i_{2}-1\right) T_{2}\right)=Q-Q_{1 n_{1}}-Q_{2 i_{2}-1}$. Solving the differential equation, we have

$$
\begin{aligned}
& I_{2 i_{2}}(t)=Q-\frac{A}{b}\left(e^{n_{1} b T_{1}}-1\right)-\left(i_{2}-1\right) A T_{2} e^{b \mu} \\
&-\left(A e^{b \mu}-\beta p_{2 i_{2}}\right)\left(t-\left(\mu+\left(i_{2}-1\right) T_{2}\right)\right) \\
&+\beta T_{1} \sum_{j=1}^{n_{1}} p_{1 j}+\beta T_{2} \sum_{j=1}^{i_{2}-1} p_{2 j} \\
& \mu+\left(i_{2}-1\right) T_{2} \leq t \leq \mu+i_{2} T_{2} .
\end{aligned}
$$


The holding cost of inventory in the time period $[\mu, \gamma]$ is given by

$$
\begin{aligned}
\mathrm{HC}_{2}=h[ & n_{2} T_{2}\left(\mathrm{Q}-\frac{A}{b}\left(e^{n_{1} b T_{1}}-1\right)\right) \\
& +\beta n_{2} T_{1} T_{2} \sum_{j=1}^{n_{1}} p_{1 j}-\frac{A \beta T_{2}^{2} n_{2}^{2} e^{b \mu}}{2} \\
& \left.+\beta T_{2}^{2} \sum_{i_{2}=1}^{n_{2}-1}\left(n_{2}-i_{2}\right) p_{2 i_{2}}+\frac{\beta T_{2}^{2}}{2} \sum_{i_{2}=1}^{n_{2}} p_{2 i_{2}}\right] .
\end{aligned}
$$

Sales revenue for time period $[\mu, \gamma]$ is

$$
\mathrm{SR}_{2}=A T_{2} e^{b \mu} \sum_{i_{2}=1}^{n_{2}} p_{2 i_{2}}-T_{2} \beta \sum_{i_{2}=1}^{n_{2}} p_{2 i_{2}}^{2}
$$

In the final time period $[\gamma, L]$, demand is a decreasing function of time. $n_{3}$ pricing cycles are considered in this period and length of each period is $T_{3}$. Therefore, we have $n_{3} T_{3}=L-\gamma$. Let $Q_{3 i_{3}}$ be sales amount from time $\gamma$ to end of $i_{3}$ th period $\left[\gamma+\left(i_{3}-1\right) T_{3}, \gamma+i_{3} T_{3}\right],\left(i_{3}=1,2, \ldots, n_{3}\right)$. Then, we have

$$
\begin{aligned}
Q_{3 i_{3}} & =\sum_{j=1}^{i_{3}} \int_{\gamma+(j-1) T_{3}}^{\gamma+j T_{3}} D\left(t, p_{3 j}\right) d t \\
& =A \frac{e^{b \mu}}{b}\left(1-e^{-i_{3} b T_{3}}\right)-\beta T_{3} \sum_{j=1}^{i_{3}} p_{3 j} .
\end{aligned}
$$

If $I_{3 i_{3}}(t),\left(i_{3}=1,2, \ldots, n_{3}\right)$ be the instantaneous level of inventory at time $t$ in $i_{3}$ th pricing cycle in time interval $[\gamma, L]$. Then the governing differential equation becomes

$$
\begin{aligned}
& \frac{d I_{3 i_{3}}(t)}{d t}=-D\left[t, p_{3 i_{3}}\right], \\
& \gamma+\left(i_{3}-1\right) T_{3} \leq t \leq \gamma+i_{3} T_{3}
\end{aligned}
$$

with initial condition $I_{3 i_{3}}\left(\gamma+\left(i_{3}-1\right) T_{3}\right)=Q-Q_{1 n_{1}}-Q_{2 n_{2}}-$ $Q_{3 i_{3}-1}$.

Solving the differential equation, we have

$$
\begin{aligned}
I_{3 i_{3}}(t)=Q & -\frac{A}{b}\left(e^{n_{1} b T_{1}}-1\right) \\
& +\beta T_{1} \sum_{j=1}^{n_{1}} p_{1 j}-A n_{2} T_{2} e^{b \mu} \\
& +\beta T_{2} \sum_{j=1}^{n_{2}} p_{2 j}+\beta T_{3} \sum_{j=1}^{i_{3}-1} p_{3 j} \\
& -\frac{A e^{b \mu}}{b}\left(1-e^{-(\gamma-t) b}\right)+\beta p_{3 i_{3}} \\
& \times\left[t-\left(\gamma+\left(i_{3}-1\right) T_{3}\right)\right] \\
\gamma+\left(i_{3}-1\right) & T_{3} \leq t \leq \gamma+i_{3} T_{3} .
\end{aligned}
$$

Holding cost of inventory in the time period $[L, \gamma]$ is given by

$$
\begin{aligned}
\mathrm{HC}_{3}=h[ & n_{3} T_{3} \mathrm{Q}-\frac{A T_{3} n_{3}}{b}\left(e^{n_{1} b T_{1}}-1\right) \\
& +\beta n_{3} T_{1} T_{3} \sum_{j=1}^{n_{1}} p_{3 j}-A n_{3} n_{2} T_{2} T_{3} e^{b \mu} \\
& -\beta n_{3} T_{3} T_{2} \sum_{j=1}^{n_{2}} p_{3 j}-A n_{3} T_{3} e^{b \mu} \\
& -\beta T_{3}^{2} \sum_{i_{3}=1}^{n_{3}-1}\left(n_{3}-i_{3}\right) p_{3 i_{3}} \\
& \left.+\frac{\beta T_{3}^{2}}{2} \sum_{i_{3}=1}^{n_{3}} p_{3 i_{3}}+\frac{A e^{b \mu}}{b^{2}}\left(1-e^{-n_{3} b T_{3}}\right)\right] .
\end{aligned}
$$

Sales revenue for time period $[L, \gamma]$ is

$$
\mathrm{SR}_{3}=\frac{A}{b} e^{b \mu}\left(e^{b T_{3}}-1\right) \sum_{i_{3}=1}^{n_{3}} p_{3 i_{3}} e^{-b i_{3} T_{3}}-\beta T_{3} \sum_{i_{3}=1}^{n_{3}} p_{3 i_{3}}^{2} .
$$

The profit function for entire time interval comprises sales revenue, holding cost, purchase cost, price change cost, and setup cost and is found as

$$
\begin{aligned}
& \pi\left(n_{1}, n_{2}, n_{3},\left\{p_{1 i_{1}}\right\},\left\{p_{2 i_{2}}\right\},\left\{p_{2 i_{2}}\right\}\right) \\
&= \mathrm{SR}_{1}+\mathrm{SR}_{2}+\mathrm{SR}_{3} \\
&-\left(\mathrm{HC}_{1}+\mathrm{HC}_{2}+\mathrm{HC}_{3}\right) \\
&-c \mathrm{Q}-c_{0}\left(n_{1}+n_{2}+n_{3}\right)-S
\end{aligned}
$$

Therefore, we have the maximization problem

$$
\text { maximize } \pi\left(n_{1}, n_{2}, n_{3},\left\{p_{1 i_{1}}\right\},\left\{p_{2 i_{2}}\right\},\left\{p_{2 i_{2}}\right\}\right)
$$

subject to

$$
\begin{aligned}
& p_{1 i_{1}} \geq 0, \quad \forall i_{1} \leq n_{1}, \\
& p_{2 i_{2}} \geq 0, \quad \forall i_{2} \leq n_{2}, \\
& p_{3 i_{3}} \geq 0, \quad \forall i_{3} \leq n_{3},
\end{aligned}
$$

where $n_{1}, n_{2}$ and $n_{3}$ are positive integers.

2.2. Analysis. In the previous subsection the profit function $\pi$ for sales season $L$ is derived. Pricing cycle lengths $T_{1}, T_{2}$, and $T_{3}$ for three time periods are different from one another and restriction on unit selling prices for the maximization of $\pi$ is also different from one another. But note that (i) total amount of inventory $Q\left(=Q_{1 n_{1}}+Q_{2 n_{2}}+Q_{3 n_{3}}\right)$ is replenished at the beginning of the season $L$, (ii) the number of price changes in the three time periods is related by $n_{1}+n_{2}+n_{3}=$ $n \leq n_{\max }$ and (iii) most importantly, initial inventory level 
of first pricing cycle of time period $[\mu, \gamma]$ is exactly equal to the excess amount of inventory after the end of last pricing cycle of the time period $[0, \mu]$. The same is assumed for the first pricing cycle of the time period $[\gamma, L]$ and last pricing period of $[\mu, \gamma]$. Thus, effects of prices on demand represented by the inventory level after depletion are inherited in both the demand transfer points $\mu$ and $\gamma$ at which the profit function is disintegrated.

Proposition 1. For given $n_{1}, n_{2}$ and $n_{3}, \pi\left(n_{1}, n_{2}, n_{3},\left\{p_{1 i_{1}}\right\}\right.$, $\left.\left\{p_{2 i_{2}}\right\},\left\{p_{3 i_{3}}\right\}\right)$ is concave.

Proof. The necessary conditions for the existence of optimal solutions are $\partial \pi / \partial p_{1 i_{1}}=0,\left(i_{1}=1,2, \ldots, n_{1}\right), \partial \pi / \partial p_{2 i_{2}}=$ $0,\left(i_{2}=1,2, \ldots, n_{2}\right)$, and $\partial \pi / \partial p_{3 i_{3}}=0,\left(i_{3}=1,2, \ldots, n_{3}\right)$. Differentiating $\pi$ with respect to $p_{1 i_{1}}, p_{2 i_{2}}$, and $p_{3 i_{3}}$ and equating it to zero, we have

$$
\begin{aligned}
p_{1 i_{1}}= & \frac{A}{2 b T_{1} \beta} e^{i_{1} b T_{1}}\left(1-e^{-b T_{1}}\right)+\frac{h T_{1}}{4}\left(2 i_{1}-1\right)+\frac{c}{2}, \\
p_{2 i_{2}}= & \frac{A e^{b \mu}}{2 \beta}+\frac{h T_{2}}{4}\left(2 i_{2}-1\right)+\frac{n_{1} h T_{1}}{2}+\frac{c}{2}, \\
p_{3 i_{3}}= & \frac{A e^{b \mu}}{2 b T_{3} \beta}\left(e^{b T_{3}}-1\right) e^{-i_{3} b T_{3}} \\
& +\frac{h T_{3}}{4}\left(2 i_{3}-1\right) \\
& +\frac{c}{2}+\frac{h\left(n_{1} T_{1}+n_{2} T_{2}\right)}{2} .
\end{aligned}
$$

Moreover, $\partial^{2} \pi / \partial p_{1 i_{1}}^{2}=-2 T_{1} \beta<0$, for $i_{1}=1,2, \ldots, n_{1}$; $\partial^{2} \pi / \partial p_{2 i_{2}}^{2}=-2 T_{2} \beta<0$, for $i_{2}=1,2, \ldots, n_{2} ; \partial^{2} \pi_{1} / \partial p_{3 i_{3}}^{2}=$ $-2 T_{3} \beta<0$, for $i_{3}=1,2, \ldots, n_{3} ; \partial^{2} \pi / \partial p_{1 i_{1}} \partial p_{1 j_{1}}=0, \partial^{2} \pi /$ $\partial p_{2 i_{2}} \partial p_{2 j_{2}}=0, \partial^{2} \pi / \partial p_{3 i_{3}} \partial p_{3 j_{3}}=0, \partial^{2} \pi / \partial p_{1 i_{1}} \partial p_{2 j_{2}}=0$, $\partial^{2} \pi / \partial p_{1 i_{1}} \partial p_{3 j_{3}}=0, \partial^{2} \pi / \partial p_{2 i_{2}} \partial p_{3 j_{3}}=0$, for $i \neq j$ and $m$ th principle minor of the Hessian matrix is of the sign $(-1)^{m}$, $m=1,2, \ldots, n_{1}+n_{2}+n_{3}$. Therefore, $\pi$ is a concave function. The constraint imposed on the objective function is also linear in nature. Hence, the stationary point found by solving (21) provides global optimal solution.

Proposition 2. In the time interval,

(a) $[0, \mu]$, for given $n_{1}$, optimal prices satisfy the relation $p_{11}<p_{12}<\cdots<p_{1 n_{1}}$.

(b) $[\mu, \gamma]$, for given $n_{2}$, optimal prices satisfy the relation $p_{21} \leq p_{22} \leq \cdots \leq p_{2 n_{2}}$.

(c) $[\gamma, L]$, for given $n_{3}$, optimal prices satisfy the relation $p_{31}>p_{32}>\cdots>p_{3 n_{3}}$ if $A e^{b \mu}>h / b \beta$.
Proof.

(a) If $m_{1}<m_{2} \leq n_{1}$, then

$$
\begin{aligned}
p_{1 m_{2}}-p_{1 m_{1}}= & \frac{A\left(1-e^{-b T_{1}}\right)}{2 b T_{1} \beta}\left(e^{m_{2} b T_{1}}-e^{m_{1} b T_{1}}\right) \\
& +\frac{h T_{1}}{4}\left(m_{2}-m_{1}\right) .
\end{aligned}
$$

Now, $m_{1}<m_{2}$ implies $p_{1 m_{2}}-p_{1 m_{1}}>0$; that is, $p_{1 i_{1}}$ increases as $i_{1}$ increases.

(b) If $m_{1}<m_{2} \leq n_{2}$, then

$$
p_{2 m_{2}}-p_{2 m_{1}}=\frac{h T_{2}}{2}\left(m_{2}-m_{1}\right)>0
$$

that is, $p_{2 i_{2}}$ increases as $i_{2}$ increases.

Note that, theoretically, if there are several pricing cycles in $[\mu, \gamma]$ then the unit selling prices of the product increase. But it does not happen in reality. For the time interval over which the demand is steady, there should be only one selling price of the product. We verify the issue in numerical example aslo.

(c) If $m_{1}<m_{2} \leq n_{3}$, then

$$
\begin{aligned}
p_{3 m_{2}}-p_{3 m_{1}}= & \frac{A e^{b \mu}\left(e^{b T_{3}}-1\right)}{2 b T_{3} \beta}\left(e^{-m_{2} b T_{3}}-e^{m_{1} b T_{3}}\right) \\
& +\frac{h T_{2}}{2}\left(m_{2}-m_{1}\right) ;
\end{aligned}
$$

neglecting higher order terms of $b$, we get

$$
p_{3 m_{2}}-p_{3 m_{1}}=-\frac{T_{3}\left(m_{3}-m_{1}\right)}{2}\left(\frac{A e^{b \mu} b}{\beta}-h\right)
$$

that is, if $A e^{b \mu} b / \beta>h$, then $p_{3 i_{3}}$ decreases as $i_{3}$ increases.

Proposition 3. For given $n_{1}, n_{2}$, and $n_{3}$, optimal selling prices attain maximum value in the final pricing cycle of $[\mu, \gamma]$ if

$$
n_{2} \geq\left\lfloor\frac{h(\gamma-\mu) n_{3}}{(L-\gamma)\left(A e^{b \mu} b / \beta-h\right)}\right\rfloor,
$$

where \lfloor\rfloor represents greatest integer not greater than its argument.

Proof. From Proposition 2, it is found that optimal selling prices increase in time intervals $[0, \mu]$ and $[\mu, \gamma]$ as $i_{1},\left(i_{1}=\right.$ $\left.1,2, \ldots, n_{1}\right)$ and $i_{2},\left(i_{2}=1,2, \ldots, n_{2}\right)$ increase. Whereas these decrease in final time phase $[\gamma, L]$ as $i_{3},\left(i_{1}=1,2, \ldots, n_{3}\right)$ increases. Therefore, it is sufficient to verify pricing relations between final pricing cycle of $[0, \mu]$ and first pricing cycle of $[\mu, \gamma]$ and between final pricing cycle of $[\mu, \gamma]$ and first pricing cycle of $[\gamma, L]$. Now,

$$
p_{21}-p_{1 n_{1}}=\left[\frac{A e^{b \mu}}{2 \beta}+\frac{h T_{2}}{4}\right]-\left[\frac{A e^{b \mu}}{2 b T_{1} \beta}\left(1-\mathrm{e}^{-b T_{1}}\right)+\frac{h T_{1}}{4}\right] .
$$


After simplification, we get

$$
p_{21}-p_{1 n_{1}}=\frac{T_{1}}{4}\left(\frac{A e^{b \mu} b}{\beta}-h\right)+\frac{h T_{1}}{4}
$$

that is, $p_{21}-p_{1 n_{1}}>0$ if $A e^{b \mu} b / \beta>h$. Therefore, optimal selling price in first pricing cycle of $[\mu, \gamma]$ is always greater than that in final selling price of $[0, \mu]$.

Similarly, difference between optimal selling price in final pricing cycle of $[\mu, \gamma]$ and first cycle of $[\gamma, L]$ is

$$
p_{2 n_{2}}-p_{31}=\left[\frac{A e^{b \mu}}{2 \beta}-\frac{h T_{2}}{4}\right]-\left[\frac{A e^{b \mu}}{2 b T_{3} \beta}\left(1-e^{-b T_{3}}\right)+\frac{h T_{3}}{4}\right]
$$

on simplification, we get

$$
p_{2 n_{2}}-p_{31}=\frac{T_{3}}{4}\left(\frac{A e^{b \mu} b}{\beta}-h\right)-\frac{h T_{2}}{4}
$$

that is, $p_{2 n_{2}}-p_{31}>0$ if $n_{2} \geq\left\lfloor h(\gamma-\mu) n_{3} /(L-\gamma)\left(A e^{b \mu} b / \beta-h\right)\right\rfloor$. Since optimal selling prices are increasing in $[0, \mu]$ and $[\mu, \gamma]$ and decreasing in $[\gamma, L]$, the proposition follows immediately.

Proposition 2 indicates that in time period $[0, \mu]$ when demand is increasing, optimal selling prices form an increasing sequence. The same pattern is followed for prices in time interval $[\mu, \gamma]$, whereas reverse trend is found for prices in $[\gamma, L]$ in which demand is decreasing. Proposition 3 indicates the time when selling price of the product is maximum. If $n_{1}, n_{2}$ and $n_{3}$ are given, then determining pricing cycles and hence time in which unit price is maximum a decision maker may apply some strategy to enhance inventory depletion rate to increase his profit.

In the next subsection using Propositions 1, 2, and 3, we develop a solution procedure in order to find optimal total profit $\pi\left(n_{1}, n_{2}, n_{3},\left\{p_{1 i_{1}}, p_{2 i_{2}}, p_{3 i_{3}}\right\}\right)$ such that $n_{1}+n_{2}+n_{3} \leq$ $n_{\max }\left(1 \leq i_{1} \leq n_{1}, 1 \leq i_{2} \leq n_{2}, 1 \leq i_{3} \leq n_{3}\right)$ through simultaneous determination of optimal values of $n_{1}, n_{2}, n_{3}$, prices $p_{1 i_{1}}, p_{2 i_{2}}, p_{3 i_{3}}$, and $Q$.

\subsection{Solution Procedure}

Step 1. Input parameter values.

Step 2. Set $n_{1}=1, n_{2}=1, n_{3}=1, \pi^{*}=0$, and $Q^{*}=0$.

Step 3. Repeat until $\left(n_{1} \leq n_{\max }-2\right)$;

repeat until $\left(n_{2} \leq n_{\max }-n_{1}-1\right)$;

repeat until $\left(n_{3} \leq n_{\max }-n_{1}-n_{2}\right)$;

for $\left(i_{1} \leq n_{1}\right),\left(i_{2} \leq n_{2}\right)$, and $\left(i_{3} \leq n_{3}\right)$;

determine $p_{1 i_{1}}, p_{2 i_{2}}$, and $p_{3 i_{3}}$;

calculate $Q$;

calculate $\pi$

if $\pi>\pi^{*}$, then $\pi=\pi^{*}, Q=Q^{*}, N=\left(n_{1}, n_{2}, n_{3}\right)$, and $P=\left(p_{1 i_{1}}, p_{2 i_{2}}, p_{3 i_{3}}\right)$ by using $(21)$.
TABLE 1: Optimal values of $(\pi, Q)$ for $n_{2}=1, n_{1}=1,2, \ldots, 4$ (rowwise) and $n_{3}=1,2,3$ (columnwise).

\begin{tabular}{cccc}
\hline & 1 & 2 & 3 \\
\hline 1 & $(7518.05,11327.71)$ & $(7762.63,11434.72)$ & $(7725.85,11471.69)$ \\
2 & $(8151.99,11111.49)$ & $(8406.14,11327.74)$ & $(8410.01,11471.46)$ \\
3 & $(8189.49,10841.53)$ & $(\mathbf{8 4 6 1 . 0 8}, \mathbf{1 1 1 1 1 . 5 6 )}$ & $(8430.91,11201.65)$ \\
4 & $(8102.12,10598.76)$ & $(8397.33,10949.12)$ & $(8372.93,11099.21)$ \\
\hline
\end{tabular}

TABLE 2: Optimal values of $(\pi, Q)$ for $n_{2}=2, n_{1}=1,2,3,4$ (rowwise) and $n_{3}=1,2,3$ (columnwise).

\begin{tabular}{cccc}
\hline & 1 & 2 & 3 \\
\hline 1 & $(7027.36,11314.20)$ & $(7453.97,11449.25)$ & $(7414.56,11494.23)$ \\
2 & $(7933.37,11111.71)$ & $(8186.84,11327.74)$ & $(8051.82,11399.71)$ \\
3 & $(7884.12,10922.71)$ & $(\mathbf{8 2 6 1 . 9 2 , 1 1 1 9 3 . 8 7 )}$ & $(8119.22,1128614)$ \\
4 & $(7808.09,10706.71)$ & $(8095.31,11084.32)$ & $(8067.94,11210.72)$ \\
\hline
\end{tabular}

Step 4. Write output.

Note that solution procedure is developed to determine optimal number of price settings and optimal prices over the entire finite time horizon $L$ through simultaneous optimization of the decision variables rather than their individual optimization in time periods $[0, \mu],[\mu, \gamma]$, and $[\gamma, L]$ respectively. Using Propositions 1, 2, and 3, optimal prices $p_{1 i_{1}}, p_{2 i_{2}}, p_{3 i_{3}}$ are determined for any fixed $n_{1}, n_{2}, n_{3}$, respectively, such that $n_{1} \leq n_{\max }-2, n_{2} \leq n_{\max }-2$, and $n_{3} \leq n_{\max }-2$. The arbitrariness of $n_{1}, n_{2}, n_{3}$ within the limits and simultaneous determination of these through maximization of $\pi$ ensure that $\pi^{*}$ will always provide global optimal solution for the problem over entire finite time horizon $L$.

\section{Numerical Example}

Assume that a retailer plans to purchase a quantity at a rate $\$ 80$ for the sales season $L=180$ days. Demand is increasing up to 90 days and it remains steady for next 30 days; that is, $\gamma=120$ days. In the rest of the sales season the demand is decreasing. Inventory holding cost, price change cost and setup cost are $\$ 0.1, \$ 2000$, and $\$ 10000$, respectively. Values of $A, b$, and $\beta$ are $50,0.02$, and 0.6 , respectively, and maximum permissible price setting is 12 . Using the solution procedure for different values of $n_{1}, n_{2}$, and $n_{3}$, profits and order quantities are calculated and presented for $n_{1}=1, \ldots, 4$, $n_{2}=1, n_{3}=1,2,3$ and $n_{1}=1, \ldots, 4, n_{2}=2, n_{3}=1$, 2, 3 in Tables 1 and 2, respectively. From Table 1, it is found that optimal profit is 8461.08 and order quantity is 11111.56 for $n_{1}=3, n_{2}=1$, and $n_{3}=2$. Note that optimal profit is not found in Table 2 . We have performed numerical calculations by considering all possible combinations of $n_{1}, n_{2}$, and $n_{3}$ within the range of $n_{\max }$. In all the cases profits are less than the profits presented in Tables 1 and 2 . Thus the results are not presented. $n_{1}=3, n_{2}=1$, and $n_{3}=2$ indicate that, there will be three different prices in the time interval $[0,90]$, one price setting in $[90,120]$ and two prices in $[90,180]$. The optimal prices are 106.84, 155.28, 242.36, 294.31, 230.30, 146.2,8 and 
TABLE 3: Sensitivity analysis of the model.

\begin{tabular}{|c|c|c|c|c|c|}
\hline Parameter & $\%$ change in value & $\left(n_{1}, n_{2}, n_{3}\right)$ & $\%$ change in $Q$ & $\pi$ & $\%$ change in $\pi$ \\
\hline \multirow{4}{*}{$A$} & -30 & $(2,1,2)$ & -42.12 & 2739.51 & -67.63 \\
\hline & -10 & $(3,1,2)$ & -14.52 & 6221.57 & -26.47 \\
\hline & 10 & $(3,1,2)$ & 14.52 & 11021.19 & 30.26 \\
\hline & 30 & $(3,1,3)$ & 43.56 & 17103.25 & 102.14 \\
\hline \multirow{4}{*}{$\beta$} & -30 & $(3,1,2)$ & 13.56 & 14983.16 & 77.08 \\
\hline & -10 & $(3,1,2)$ & 4.52 & 10126.35 & 19.68 \\
\hline & 10 & $(3,1,2)$ & -4.52 & 7119.77 & -15.85 \\
\hline & 30 & $(3,1,2)$ & -13.56 & 5109.75 & -39.61 \\
\hline \multirow{4}{*}{$b$} & -30 & $(2,1,1)$ & -48.86 & 1788.54 & -78.86 \\
\hline & -10 & $(2,1,2)$ & -17.26 & 5314.46 & -37.19 \\
\hline & 10 & $(3,1,3)$ & 22.67 & 13051.88 & 54.26 \\
\hline & 30 & $(4,1,3)$ & 76.60 & 29382.21 & 247.26 \\
\hline \multirow{4}{*}{$c$} & -30 & $(3,1,2)$ & 11.66 & 10057.81 & 18.87 \\
\hline & -10 & $(3,1,2)$ & 3.89 & 8974.14 & 6.06 \\
\hline & 10 & $(3,1,2)$ & -3.89 & 7967.23 & -5.84 \\
\hline & 30 & $(3,1,2)$ & -11.66 & 7037.12 & -16.83 \\
\hline \multirow{4}{*}{$c_{0}$} & -30 & $(5,1,6)$ & 0.03 & 725558 & 0.47 \\
\hline & -10 & $(4,1,6)$ & 0.01 & 723234 & 0.15 \\
\hline & 10 & $(4,1,5)$ & 0.00 & 721055 & -0.15 \\
\hline & 30 & $(4,1,5)$ & -0.01 & 719055 & -0.43 \\
\hline \multirow{4}{*}{$h$} & -30 & $(3,1,3)$ & 0.81 & 8664.24 & 2.41 \\
\hline & -10 & $(3,1,2)$ & 0.00 & 8527.75 & 0.79 \\
\hline & 10 & $(3,1,2)$ & -0.01 & 8394.92 & -0.78 \\
\hline & 30 & $(3,1,2)$ & -0.25 & 8261.08 & -2.36 \\
\hline
\end{tabular}

are set in the time intervals $[0,30],[30,60],[60,90],[90,120]$, $[120,150]$, and $[150,180]$, respectively. Three prices are set in the time interval $[0,90]$ each of 30 -days length and prices are increasing, which agrees with Proposition 2(a). Similarly, two prices are set in the time interval $[120,180]$ and prices are decreasing. In time interval $[90,120]$, demand becomes steady and only one price is set in this time interval. This is quite obvious and we never find more than one price change in this time interval because higher unit selling price induces customers in more negative way. It results lower demand per unit time and hence lower volume of profit. The nature of price settings for different demand patterns in different time phases is similar to the characteristics of the price setting in real market. Since seasonal products as sales season progress selling price of the product increases for the increment of market potential and finally it assumes the maximum and towards end of season it decreases for decrement of market potential. However, maximum optimal selling price is 294.31 and it is found in time interval $[\mu, \gamma]$, which agrees with the finding of Proposition 3. This is quite natural and agrees with the pricing strategy of a monopolist for seasonal products. Since market potential for the product in $[\mu, \gamma]$ is maximum for the sales season, it is a common practice in marketing that increment of market potential should be capitalized through higher selling price. It also ensures customers about the quality of the product. From Table 1, it is also found that for static pricing strategy; that is, for $n_{1}=n_{2}=$ $n_{3}=1$, optimal profit and optimal order quantity are 7518.05 and 11327.71, respectively. Optimal profit for dynamic pricing is $12.54 \%$ higher than that of static pricing strategy. Thus, dynamic pricing strategy completely outperforms static pricing strategy. Hence, it is always preferable to static pricing strategy in decision making context.

In Table 3, some sensitivity analysis of the model is performed by changing parameter values $-30 \%,-10 \%, 10 \%$, and $30 \%$, taking one at a time and keeping remaining unchanged. It is found from Table 3 that the model is highly sensitive to error in estimation of parameter values $A, b$, and 
$\beta$. Moderate sensitivity to change in parameter value $c$ and low sensitivity are found for parameters $c_{0}$ and $h . A, b$ are demand parameters. Changes of $A$ and $b$ highly influence increment or decrement of demand rate, and hence profit, whereas, $\beta$ is price sensitive parameter in demand. Error in estimation of $\beta$ leads to either positive or negative impact on demand, resulting higher or lower volume of profit.

\section{Summary and Concluding Remarks}

This paper is based on time- and price-dependent ramptype demand rate for perishable inventory. Considering three profit functions for ramp-up, ramp-down, and steady demand periods optimal selling prices and optimal order quantity are determined for entire sales season. Optimal selling prices are determined in different way from the previous research works because the present paper assumes that the number of price setting is a decision variable. The analytical result shows that for any number of price changes within the limit over the finite time horizon, it is always possible to determine optimal sales prices as well as the order quantity. It is also shown that in ramp up and steady demand's time periods, optimal prices increase, whereas for ramp down time period optimal prices decrease monotonically. Thus, optimal prices always attain maximum value either in steady demand period or in final pricing cycle of $[0, \mu]$. An algorithm is provided in order to determine optimal number of price setting in three time periods simultaneously such that total profit over the entire time horizon is maximum. A numerical example is presented which agrees with all analytical findings.

The model presented here is in full accord with basic micro economic principle of seasonal products. Moreover, one can easily encode the logic used in this paper to develop an ERP module for products which have limited sales season and demand structure as cited above. The model may be extended to production inventory model or economic order quantity model with noninstantaneous receipt. These two are basically the same in mathematical sense but applicable to manufacturing industry and retail business, respectively. An interesting area of future investigation is to determine the optimal price settings for replenishment-production batching policy under ramp-type demand structure, which none has tried to enter into.

\section{References}

[1] R. M. Hill, "Inventory models for increasing demand followed by level demand," Journal of the Operational Research Society, vol. 46, no. 10, pp. 1250-1259, 1995.

[2] B. Mandal and A. K. Pal, "Order level inventory system with ramp type demand rate for deteriorating items," Journal of Interdisciplinary Mathematics, vol. 1, pp. 49-66, 1998.

[3] K. S. Wu and L. Y. Ouyang, "A replenishment policy for deteriorating items with ramp type demand rate," Proceedings of the National Science Council, Republic of China A, vol. 24, no. 4, pp. 279-286, 2000.

[4] K. S. Wu, "An EOQ inventory model for items with Weibull distribution deterioration, ramp type demand rate and partial backlogging," Production Planning and Control, vol. 12, no. 8, pp. 787-793, 2001.

[5] B. C. Giri, A. K. Jalan, and K. S. Chaudhuri, "Economic Order Quantity model with Weibull deterioration distribution, shortage and ramp-type demand," International Journal of Systems Science, vol. 34, no. 4, pp. 237-243, 2003.

[6] S. K. Manna and K. S. Chaudhuri, "An EOQ model with ramp type demand rate, time dependent deterioration rate, unit production cost and shortages," European Journal of Operational Research, vol. 171, no. 2, pp. 557-566, 2006.

[7] P. S. Deng, R. H. J. Lin, and P. Chu, "A note on the inventory models for deteriorating items with ramp type demand rate," European Journal of Operational Research, vol. 178, no. 1, pp. 112120, 2007.

[8] S. Panda, S. Saha, and M. Basu, "An EOQ model with generalized ramp-type demand and weibull distribution deterioration," Asia-Pacific Journal of Operational Research, vol. 24, no. 1, pp. 93-109, 2007.

[9] S. Panda, S. Senapati, and M. Basu, "Optimal replenishment policy for perishable seasonal products in a season with ramptype time dependent demand," Computers and Industrial Engineering, vol. 54, no. 2, pp. 301-314, 2008.

[10] M. Cheng and G. Wang, "A note on the inventory model for deteriorating items with trapezoidal type demand rate," Computers and Industrial Engineering, vol. 56, no. 4, pp. 12961300, 2009.

[11] S. Panda, S. Saha, and M. Basu, "Optimal production stopping time for perishable products with ramp-type quadratic demand dependent production and setup cost," Central European Journal of Operations Research, vol. 17, no. 4, pp. 381-396, 2009.

[12] K. Skouri, I. Konstantaras, S. Papachristos, and I. Ganas, "Inventory models with ramp type demand rate, partial backlogging and Weibull deterioration rate," European Journal of Operational Research, vol. 192, no. 1, pp. 79-92, 2009.

[13] K. C. Hung, "An inventory model with generalized type demand, deterioration and backorder rates," European Journal of Operational Research, vol. 208, no. 3, pp. 239-242, 2011.

[14] S. Saha and M. Basu, "Integrated dynamic pricing for seasonal products with price and time dependent demand," Asia-Pacific Journal of Operational Research, vol. 27, no. 3, pp. 1-17, 2010.

[15] P. Kotler and G. Armstrong, Principles of Marketing, PrenticsHall of India, 2007.

[16] T. L. Urban and R. C. Baker, "Optimal ordering and pricing policies in a single-period environment with multivariate demand and markdowns," European Journal of Operational Research, vol. 103, no. 3, pp. 573-583, 1997.

[17] S. W. Shinn and H. Hwang, "Optimal pricing and ordering policies for retailers under order-size-dependent delay in payments," Computers and Operations Research, vol. 30, no. 1, pp. 35-50, 2003.

[18] D. S. Dave, K. E. Fitzpatrick, and J. R. Baker, "An advertisinginclusive production lot size model under continuous discount pricing," Computers and Industrial Engineering, vol. 30, no. 1, pp. 147-159, 1996.

[19] N. H. Shah and Y. K. Shah, "An EOQ model for exponentially decaying inventory under temporary price discounts," Cahiers du CERO, vol. 35, pp. 227-232, 1993.

[20] H. M. Wee and S. T. Law, "Replenishment and pricing policy for deteriorating items taking into account the time-value of money," International Journal of Production Economics, vol. 71, no. 1-3, pp. 213-220, 2001. 
[21] M. J. Khouja, "Optimal ordering, discounting, and pricing in the single-period problem," International Journal of Production Economics, vol. 65, no. 2, pp. 201-216, 2000.

[22] C. C. Wu, C. Y. Chou, and C. Huang, "Optimal price, warranty length and production rate for free replacement policy in the static demand market," Omega, vol. 37, no. 1, pp. 29-39, 2009.

[23] S. Transchel and S. Minner, "The impact of dynamic pricing on the economic order decision," European Journal of Operational Research, vol. 198, no. 3, pp. 773-789, 2009.

[24] S. Netessine, "Dynamic pricing of inventory/capacity with infrequent price changes," European Journal of Operational Research, vol. 174, no. 1, pp. 553-580, 2006.

[25] E. Adida and G. Perakis, "A nonlinear continuous time optimal control model of dynamic pricing and inventory control with no backorders," Naval Research Logistics, vol. 54, no. 7, pp. 767-795, 2007.

[26] W. Elmaghraby and P. Keskinocak, "Dynamic pricing in the presence of inventory considerations: research overview, current practices, and future directions," Management Science, vol. 49, no. 10, pp. 1287-1309, 2003. 


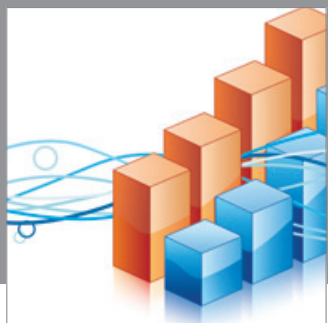

Advances in

Operations Research

mansans

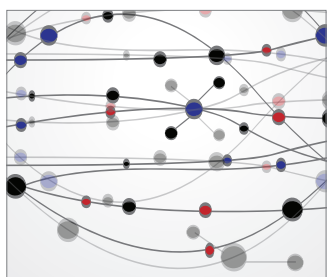

The Scientific World Journal
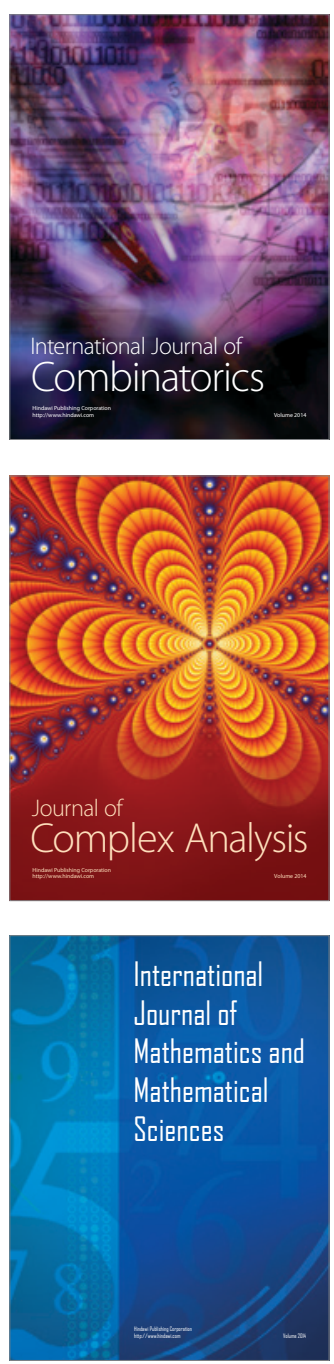
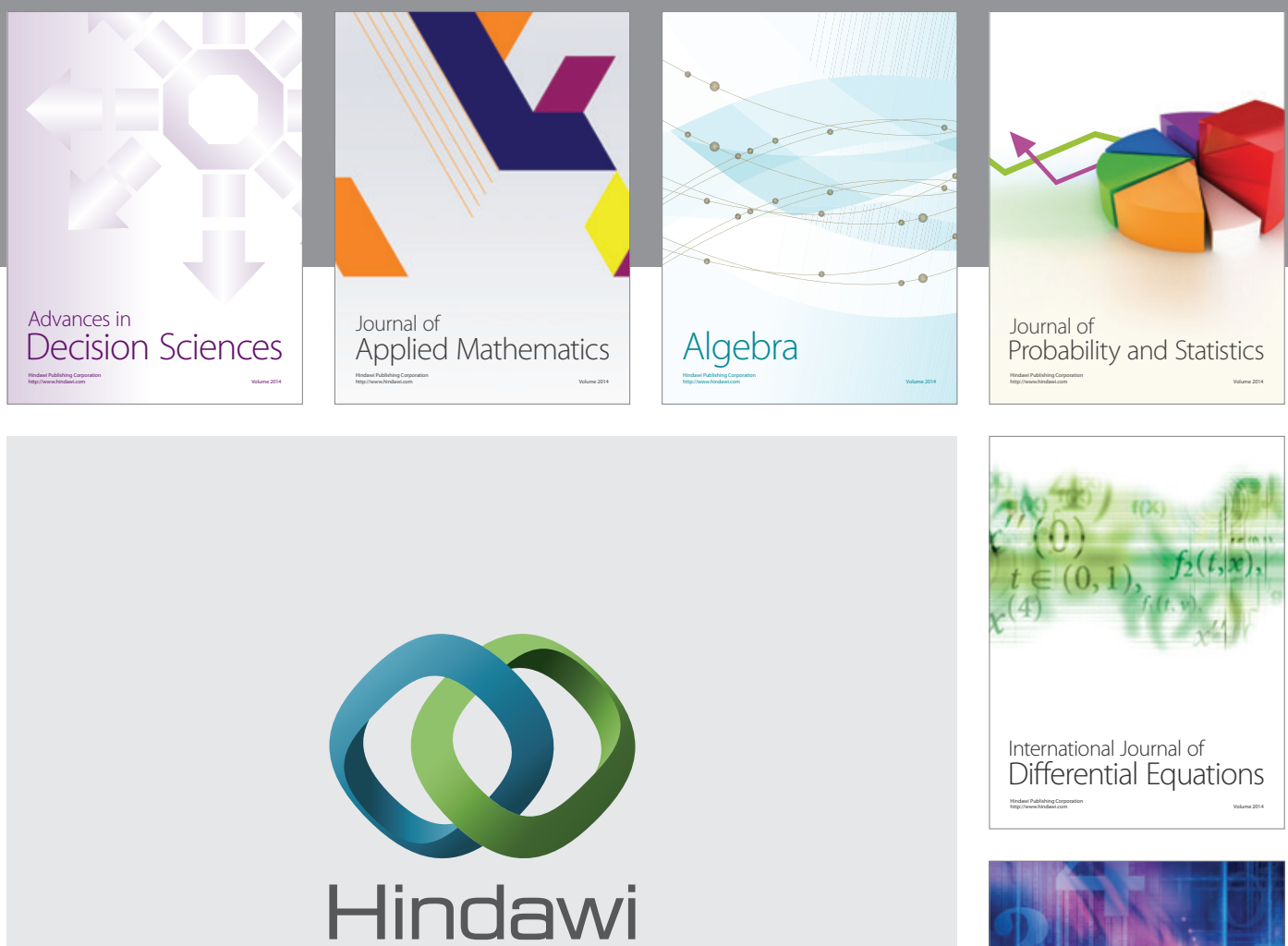

Submit your manuscripts at http://www.hindawi.com
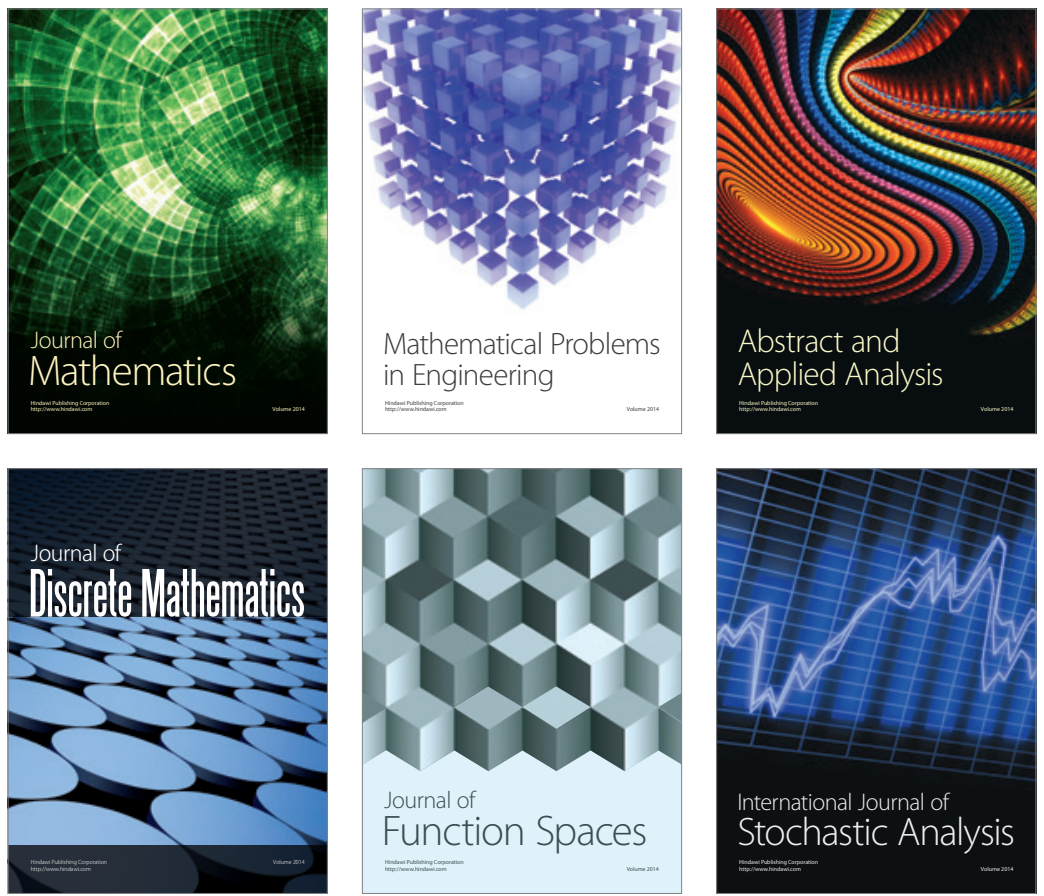

Journal of

Function Spaces

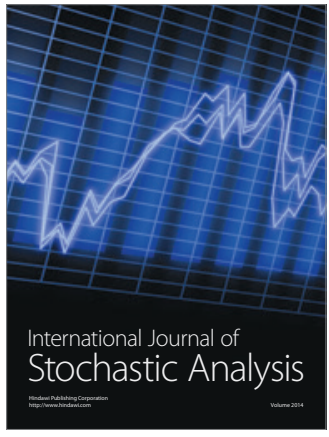

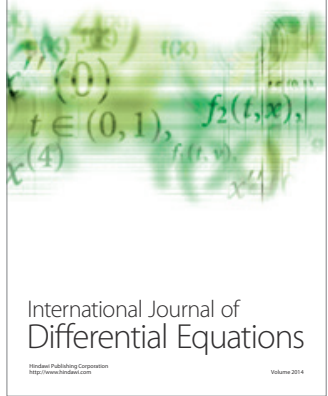
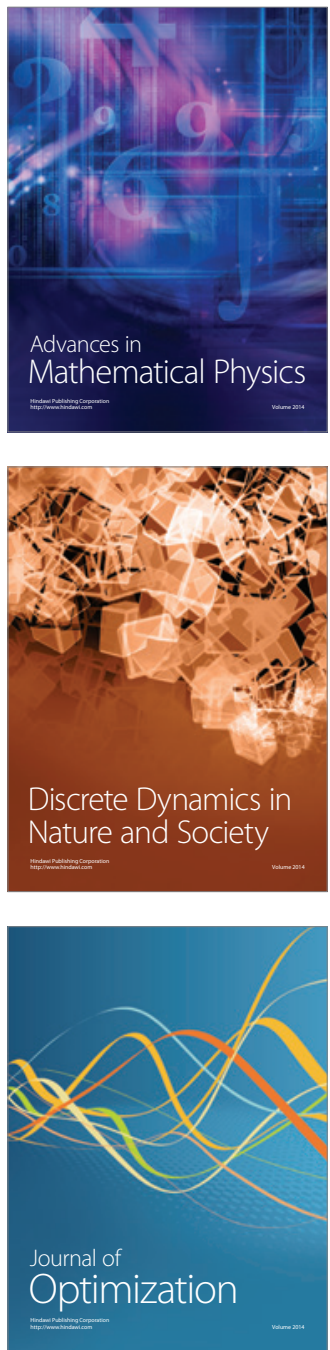